\title{
Daily Solar Irradiance Fluctuation Assessment Method Based on Correlation Analysis
}

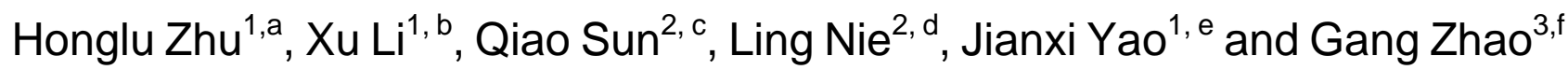 \\ ${ }^{1}$ State Key Laboratory of Alternate Electrical Power System with Renewable Energy Sources, North \\ China Electric Power University, Beijing 102206, China; \\ ${ }^{2}$ Guodiantong Network Technology Co., Beijing 100070, China; \\ ${ }^{3}$ School of Electronic Engineering, Xidian University, Xian 710071, China. \\ a hongluzhu@126.com, ${ }^{b}$ lixu_ncepu@126.com, ${ }^{\text {c }}$ sunqiao@sgepri.sgcc.com.cn, ${ }^{\mathrm{d}}$ \\ nieling@sgepri.sgcc.com.cn, ${ }^{\mathrm{e}}$ jianxiyao@ncepu.edu.cn, ${ }^{\dagger}$ gangzhao@mail.xidian.edu.cn
}

Keywords: solar irradiance assessment, diurnal variation, fluctuation.

\begin{abstract}
A method to evaluate fluctuation characteristics of daily solar irradiance was introduced based on theoretical solar irradiance. Process feature of daily solar irradiance were analyzed. Observed daily solar irradiance of 10 days in Beijing was tested to demonstrate the effectiveness of this method. Result shows that method proposed in this paper can reflect fluctuation characteristics of daily solar irradiance well and will be helpful for solar power application.
\end{abstract}

\section{Introduction}

In the long run, solar power generation owns resource, technological and environmental advantages in becoming strategic energy resource in around 2030. According to statistical data of National Energy Administration in China, 10.6GW PV was installed in 2014, and accumulated installed capacity by 2014 was 28.05GW [1]. Meanwhile, National Energy Administration proposed that construction scale of domestic newly installed PV capacity would reach 17.8GW in 2015[2]. Solar resource assessment is the foundation of scientific planning and designing of PV power station and has important significance for improving the exploitation and utilization of PV power station.

Fluctuation of daily solar irradiation is jointly influenced by astronomical motions, meteorological conditions and atmospheric environment quality. Random fluctuations of daily solar irradiance have already been the object of several studies published in the literatures[3-5]. Harrouni and Guessoum [3] introduced the estimated fractal dimension $(\hat{D})$ and the clearness index $(K T)$ as classification criteria of daily solar irradiance. Perpiñán and Lorenzo[4] analyzed the irradiance fluctuations with some mathematical tools based on the wavelet transform. What's more, some paper describes a definition of the irradiance fluctuation degree by using original parameter, moving average and standard deviation of irradiance data[5]. In this paper, theoretical solar irradiance was introduced as analysis foundation and a method to analyze and evaluate fluctuation characteristics of daily solar irradiance was proposed with correlation coefficient $(r)$.

This paper is organized as follows: the second section described the overall solar resource in Beijing. In the third section, assessment method of fluctuation of daily solar irradiance was introduced. Finally, analysis results of variability in daily solar irradiance for multiple days are provided in the fourth section. Solar resource in Beijing $\left(40.089^{\circ} \mathrm{N}, 116.306^{\circ} \mathrm{E}\right)$ is treated as the analysis object in this section.

\section{Fluctuation of Daily Solar Irradiation}

Natural conditions in Beijing own abundant advantages in the development and utilization of solar energy. Meteorological data shows that annual sunshine duration in Beijing reaches about 2600h, and annual solar irradiation reaches about $5200 \mathrm{MJ} / \mathrm{m}^{2}$. According to meteorological industrial standard QX/T 89-2008 Evaluation method for solar energy resources, the richness level is abundant. Curve of 
monthly average global horizontal irradiation in Beijing (1958-2010) presents unimodal shape, as shown in Fig.1. The database of NASA Surface Meteorology and Solar Energy points out that maximum monthly average value appears in May $\left(191.27 \mathrm{kWh} / \mathrm{m}^{2}\right)$, and minimum monthly average value appears in December $\left(76.57 \mathrm{kWh} / \mathrm{m}^{2}\right)$. The above analysis results indicate that solar resource assessment based on the standard[6] can provide an overview of solar resource for the area where PV power station plans to be built.

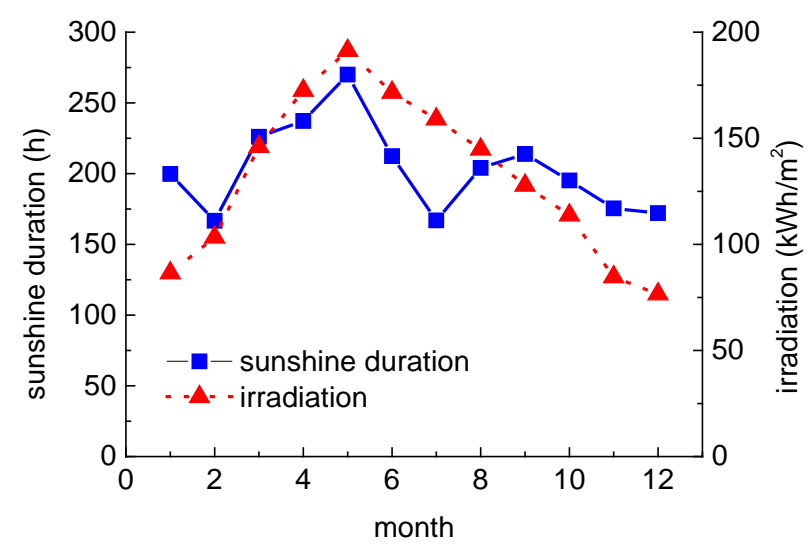

Fig. 1 Monthly average global horizontal irradiation and sunshine duration in Beijing (The solid line is monthly average sunshine duration between 2010-2012, data from the Beijing Statistical Yearbook; the dotted line is the monthly average global horizontal irradiation, data from the NASA Surface Meteorology and Solar Energy)

Curves of daily solar irradiance under clear day in four seasons are shown in Fig.2, where the solid line represents observed solar irradiance; imaginary line represents the theoretical solar irradiance on that day; four colors correspond to four seasons. It is known from Fig.2 that, due to the effect of astronomical motions, daily global horizontal solar irradiance has significant differences in different seasons. Generally, it is rich in summer, followed by spring and fall, and poor in winter.

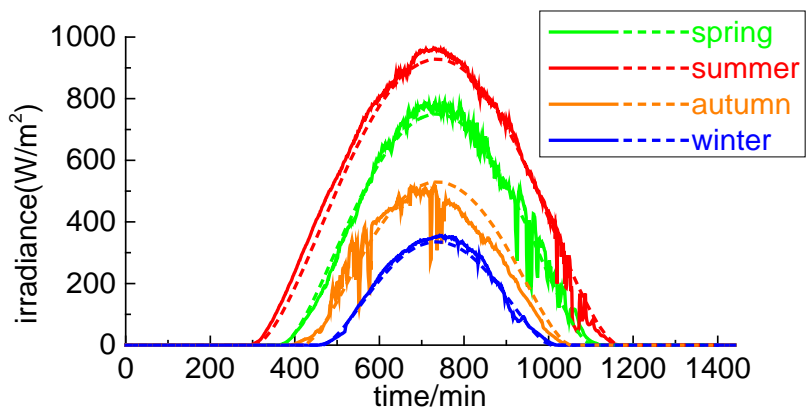

Fig. 2 Daily solar irradiance in four seasons

\section{Assessment Method of Fluctuation of Daily Solar Irradiance}

\section{Calculation of Theoretical Solar Irradiance.}

Theoretical Solar Irradiance is the global irradiance reaching the horizontal plane on the earth surface without considering the effects of cloud layer and meteorological factor, only based on the relative movement between the earth and the sun. It is the sum of beam horizontal irradiance and diffuse horizontal irradiance, with the former one occupies the most part of it in clear day, the calculation formula [7] is shown in equation (1):

$$
T(i)=G_{c b}+G_{c d}=G_{0} \times\left\{0.271+0.706 \times\left[a_{0}+a_{1} \times \exp \left(-\frac{k}{\sin h}\right)\right]\right\}
$$


Where, $i$ is time or sampling point; $G_{c b}$ is beam horizontal irradiance ; $G_{c d}$ is diffuse horizontal irradiance; $G_{0}$ is extraterrestrial solar irradiance; $a_{0}, a_{1}, k$ is empirical parameters, which are given by Duffie and Beckman [8] and related to the local climate and altitude.

In this paper, fluctuation features of observed daily solar irradiance were analyzed by referring to theoretical solar irradiance, which can eliminate the periodicity and non-stability feature of solar irradiance due to the effects of season and geography.

\section{Analysis of Fluctuation Process of Daily Solar Irradiance.}

In this section, correlation coefficient is selected to describe the process characteristic of deviation value between observed solar irradiance curve and theoretical curve over time, assumed as $r$. Correlation coefficient is a quantity to study linear dependence among variables. Before calculating correlation coefficient, it is necessary to firstly carry out differential treatment of both observed and theoretical solar irradiance curve, as shown in equation (2):

$$
\left\{\begin{array}{l}
\Delta M(i)=M(i+1)-M(i) \\
\Delta T(i)=T(i+1)-T(i)
\end{array}\right.
$$

The computational formula of correlation coefficient between difference sequence of observed irradiance $\{\Delta M(i)\}$ and difference sequence of theoretical irradiance $\{\Delta T(i)\}$ is shown in equation (3):

$$
r=\frac{\sum_{i=1}^{N-1}[\Delta M(i)-\overline{\Delta M(i)}]^{2}[\Delta T(i)-\overline{\Delta T(i)}]^{2}}{\sqrt{\sum_{i=1}^{N-1}[\Delta M(i)-\overline{\Delta M(i)}]^{2}} \sqrt{\sum_{i=1}^{N-1}[\Delta T(i)-\overline{\Delta T(i)}]^{2}}}
$$

Where, $\overline{\Delta M(i)}$ is daily average value of difference sequence of observed irradiance; $i$ is serial number of sampling points, $i=1,2,3 \cdots N ; N$ is the number of sampling points.

According to the nature of correlation coefficient, calculation results of correlation coefficient can be divided into three grades: $|r|<0.4$ means two variables are of low linear correlation; $0.4 \leq|r|<0.7$ means two variables are of significant correlation; $0.7 \leq|r|<1$ two variables are of high linear correlation. The coincidence degree of observed irradiance curve and theoretical irradiance curve expressed with correlation coefficient can reflect fluctuation process feature of observed irradiance curve. The smaller correlation coefficient is, the more server fluctuation is.

\section{Experimental Section}

Observed data of 10 days at random from January to June in 2015 are chosen for analysis. Table 1 illustrates fluctuations of daily solar irradiance for multiple days under different weather conditions. These 10 days serve as the representative of solar irradiance in Beijing in the first half year. The maximum value of daily global horizontal irradiation is $7.713 \mathrm{kWh} / \mathrm{m}^{2}$, and the minimum value is $1.348 \mathrm{kWh} / \mathrm{m}^{2}$, with the average value of $5.044 \mathrm{kWh} / \mathrm{m}^{2}$ which is higher than annual average level (according to meteorological database of NASA, daily average global horizontal irradiation is 4.32 $\mathrm{kWh} / \mathrm{m}^{2}$ in Beijing). The maximum value of correlation coefficient $r$ is 0.980 , and the minimum value is 0.145 . 
Table 1 Fluctuations of daily solar irradiance of several days

\begin{tabular}{|c|c|c|c|}
\hline Date & Weather condition & $\begin{array}{l}\text { daily global } \\
\text { irradiation } \\
\left(\mathrm{kWh} / \mathrm{m}^{2}\right)\end{array}$ & $\begin{array}{c}\text { Correlation } \\
\text { coefficient }(r)\end{array}$ \\
\hline 20150429 & Clear & 6.175 & 0.980 \\
\hline 20150503 & Mostly cloudy \& Partly clear & 5.307 & 0.223 \\
\hline 20150504 & Clear \& Scattered clouds & 7.227 & 0.644 \\
\hline 20150508 & $\begin{array}{l}\text { Mist } \sim \text { Haze } \sim \text { Clear } \& \\
\text { Mostly cloudy }\end{array}$ & 5.480 & 0.452 \\
\hline 20150509 & Cloudy & 1.348 & 0.145 \\
\hline 20150511 & Rain & 1.606 & 0.261 \\
\hline 20150528 & Clear & 7.713 & 0.894 \\
\hline 20150605 & $\begin{array}{l}\text { Haze } \sim \text { Clear \& Mostly } \\
\text { cloudy }\end{array}$ & 6.773 & 0.397 \\
\hline 20150610 & $\begin{array}{l}\text { Light rain showers } \sim \text { Mist } \& \\
\text { Haze } \sim \text { thunderstorms \& rain }\end{array}$ & 4.880 & 0.210 \\
\hline 20150615 & Thunderstorms & 3.933 & 0.275 \\
\hline
\end{tabular}

Four typical weather conditions (clear, cloudy, overcast, rainy) are chosen from the sample database for further analysis. Fig.3 shows process feature of daily solar irradiance fluctuation under four typical weather conditions. The curve is the result of observed irradiance curve and theoretical irradiance curve after differential treatment.
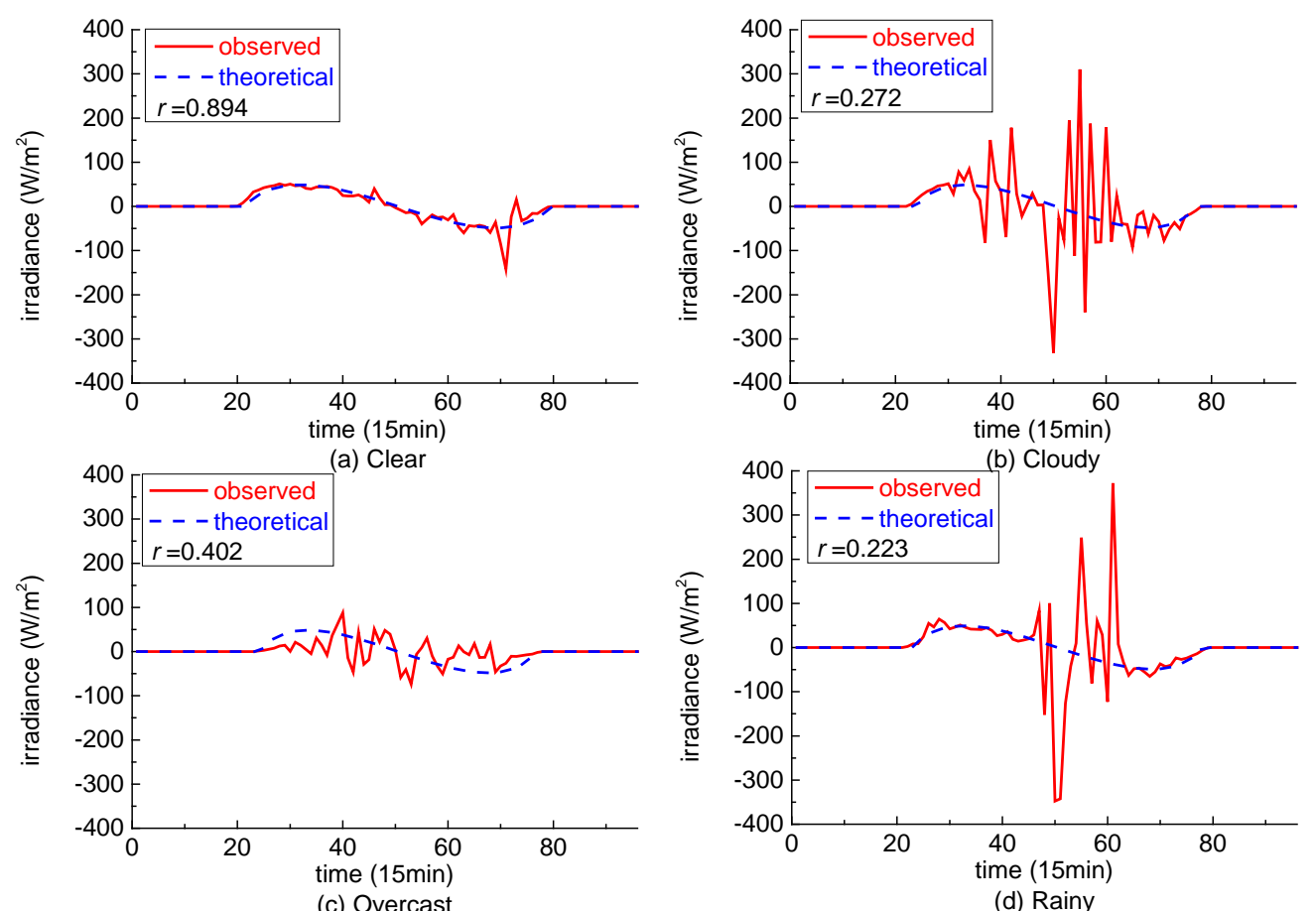

Fig. 3 Process feature of fluctuations of daily solar resources under four typical weather conditions.

\section{Summary}

Theoretical solar irradiance can eliminate effect of weather, seasons and geographic position on observed solar irradiance. An assessment method for fluctuation of daily solar irradiance was proposed in this paper based on theoretical solar irradiance. Correlation coefficient $r$ is adopted to describe process feature of daily solar resources fluctuation. Example indicates that this method can well master features of fluctuation. 


\section{Acknowledgments}

The authors would like to acknowledge the financial support of the Beijing Higher Education Young Elite Teacher Project (YETP0714), the Program of the Co-Construction with Beijing Municipal Commission of Education, State Key Laboratory of Alternate Electrical Power System with Renewable Energy Sources (LAPS14006).

\section{References}

[1]. Information on: http://www.nea.gov.cn/2015-03/09/c_134049519.htm

[2]. Information on: http://zfxxgk.nea.gov.cn/auto87/201503/t20150318_1891.htm

[3]. Harrouni S., Guessoum A., Maafi A.. Classification of daily solar irradiation by fractional analysis of 10-min-means of solar irradiance. Theoretical and Applied Climatology. Vol. 80 (2004) No. 1, p. 27-36.

[4]. Perpiñán O., Lorenzo E.. Analysis and synthesis of the variability of irradiance and PV power time series with the wavelet transform. Solar Energy. Vol. 85 (2011) No. 1, p. 188-197.

[5]. Kawasaki N., Oozeki T., Otani K. , et al. An evaluation method of the fluctuation characteristics of photovoltaic systems by using frequency analysis. Solar Energy Materials and Solar Cells. Vol. 90 (2006) No. 18-19, p. 3356-3363.

[6]. Jiangxi Climate Center, Jiangxi Meteorological Bureau. QX/T 89-2008 Assessment method for solar energy resources. China Meteorological Press, 2008, p. 1-10.

[7]. Alam S., Kaushik S.C., Garg S.N.. Computation of beam solar radiation at normal incidence using artificial neural network. Renewable Energy. Vol. 31 (2006), p. 1483-1491.

[8]. Duffie J.A., Beckman W.A.. Solar engineering of thermal processes. Wiley, 1991, p. 43-133. 